\title{
Osteoporosis and osteopenia in adults and adolescents with cystic fibrosis: prevalence and associated factors
}

\author{
S P Conway, A M Morton, B Oldroyd, J G Truscott, H White, A H Smith, I Haigh
}

\begin{abstract}
Background-Patients with cystic fibrosis (CF) have many risk factors for reduced bone mineral density (BMD). The aim of this study was to determine the prevalence of osteoporosis and osteopenia in a large cross section of patients and to identify risk factors.
\end{abstract}

Methods-All patients attending the regional centre were invited to participate in the study. Bone mineral density was measured at the lumbar spine, femoral neck, and for total body with a Lunar DPX-L densitometer. Multiple indices of disease severity were investigated, and liver and thyroid function, blood calcium, phosphate, 25-OH vitamin $D$, follicle stimulating and luteinising hormone, oestradiol, and testosterone levels were measured. Patients completed a four day prospective dietary diary. Exercise was assessed by a seven day activity recall questionnaire. Sexual development and treatment histories were obtained. The relationship between all these variables and BMD measurements was analysed. Results-Sixty six percent of 114 patients assessed had osteopenia or osteoporosis. The Shwachman-Kulczycki (SK) clinical score (higher score $=$ less severe disease) correlated significantly with BMD at the lumbar spine and femoral neck, and with total body BMD $(p<0.001)$. There was a predicted increase of $0.0032 \mathrm{~g} / \mathrm{cm}^{2}$ in lumbar spine BMD for every unit increase in the SK score. Oral steroid use was significantly associated with reduced BMD at the lumbar spine $(p=0.017)$ and femoral neck $(p=0.027)$.

Conclusions-Osteopenia and osteoporosis are common findings in a heterogeneous population of adults with CF. Patients at most risk are those with severe disease and those who have used corticosteroids. (Thorax 2000;55:798-804)

Keywords: cystic fibrosis; osteoporosis; osteopenia; corticosteroids

Mean survival for patients with cystic fibrosis (CF) in the UK has increased from approximately 18 years for those born between 1968 and 1970 to a current survival of just over 30 years of age. ${ }^{1}$ Better survival has resulted in adult patients with lung function compatible with lengthy survival but at risk of medical complications that threaten longevity and quality of life. Patients with CF have multiple risk factors for inadequate bone mineralisation-for example, poor nutrition, pancreatic insufficiency and malabsorption, calcium and vitamin D deficiency, reduced weight bearing activity, delayed puberty, hypogonadism, diabetes mellitus, and chronic infection. Osteoporosis increases the risk of fracture 2-3-fold for each standard deviation fall in the bone mineral density (BMD) below the mean for a healthy population of the same age. ${ }^{2}$ Fractures in patients with CF result in pain and disability. Structural chest wall changes following vertebral and rib fractures may result in an accelerated decline in lung function.

In 1979 Mischler documented the first evidence for reduced BMD in patients with CF using direct photon absorptiometry. ${ }^{3}$ Twelve (44\%) of 27 patients aged 5-24 years showed significant deficiency. Other studies have confirmed osteopenia and osteoporosis to be common, ${ }^{4-10}$ especially in adults with severe disease. ${ }^{11-14}$ Only one other paper has addressed the problem of inadequate bone mineralisation in a large unselected group of adult patients with $\mathrm{CF},{ }^{15}$ documenting a significant reduction in $\mathrm{BMD}$ in $34 \%$ of patients. Inadequate bone mineralisation was related to markers of disease severity and less physical activity. The aim of this study was to assess the prevalence of osteoporosis and osteopenia in a large heterogeneous population of adults and adolescents with $\mathrm{CF}$ and to assess the aetiological importance of possible risk factors. Our study, temporally overlapping with that of Haworth et $a l^{15}$ and comprising a similar group of patients in the north of England, expands our understanding of osteoporosis and osteopenia in adults with $\mathrm{CF}$.

\section{Methods}

SUBJECTS

Patients at the regional adult CF centre were invited to participate in the study. There were no special selection criteria. CF had been confirmed by identification of two CF gene mutations or by two diagnostic sweat tests. Patients were asked if they had ever sustained a fracture and, if so, details of these were recorded. Adolescents were defined as those aged 16-19.9 years and adults as 20 years of age or over.

One hundred and fourteen patients (53 male) were assessed (table 1). Height, weight, and body mass index (BMI) for the adolescents were compared with the 1990 British reference values $^{16}{ }^{17}$ and expressed as standard deviation 
Table 1 Patient characteristics of study groups

\begin{tabular}{|c|c|c|c|c|}
\hline & \multicolumn{2}{|l|}{ Adolescents } & \multicolumn{2}{|l|}{ Adults } \\
\hline & Females $(n=21)$ & Males $(n=16)$ & Females $(n=40)$ & Males $(n=37)$ \\
\hline Age (years) & $18.4 \quad(1.0)$ & $18.7(0.8)$ & $28.2(5.7)$ & $26.6(5.6)$ \\
\hline Height $(\mathrm{cm})$ & $159.8 \quad(6.4)$ & $164.4(7.9)$ & $161.1(6.3)$ & $172.3(6.8)$ \\
\hline Weight (kg) & $47.8 \quad(6.4)$ & $56.6(7.3)$ & $52.3(8.0)$ & $61.4(9.3)$ \\
\hline $\mathrm{BMI}\left(\mathrm{kg} / \mathrm{m}^{2}\right)$ & $18.7 \quad(2.1)$ & $19.5(2.9)$ & $20.0(2.1)$ & $20.6(2.4)$ \\
\hline SDS-height & $-0.6(1.1)^{\star}$ & $-1.0(0.7)^{\star \star}$ & & \\
\hline SDS — weight & $-1.5(1.1)^{\star \star}$ & $-1.5(1.1)^{\star \star}$ & & \\
\hline SDS-BMI & $-1.25(1.1)^{\star \star}$ & $-1.1(1.6)^{\star}$ & & \\
\hline
\end{tabular}

$\mathrm{BMI}=$ body mass index SDS $=$ standard deviation score .

Values are mean (SD).

${ }^{\star} \mathrm{p}=0.01,{ }^{\star \star} \mathrm{p}<0.001$ significantly different from zero.

scores. Sixty six patients (58\%) were homozygous and $36(31 \%)$ heterozygous for the delta F508 mutation. Forty (35\%) had diabetes mellitus and 61 (54\%) had CF associated liver disease as shown by abnormal liver ultrasound findings and/or persistently raised alkaline phosphatase or alanine transaminase values. One hundred and two patients (89\%) were chronically infected with Pseudomonas aeruginosa and 11 (10\%) with Burkholderia cepacia.

Patients were described in terms of their clinical status, BMI, percentage predicted value of the forced expiratory volume in one second $\left(\mathrm{FEV}_{1}\right)$, forced vital capacity (FVC), and the average forced expiratory flow rate over the middle $50 \%$ of the FVC $\left(\mathrm{FEF}_{25-75 \%}\right)$, mean number of intravenous antibiotic treatments per year over the previous five years, the Shwachman-Kulczycki (SK) clinical score, ${ }^{18}$ and the Northern chest radiography score. ${ }^{19}$ The maximum SK score is 100 , with a higher score indicating better health. Median values were 70 (range 40-100) for the SK score, 12 (range 0-19) for the Northern score, 20.2 (range 15.5-26.9) for BMI, 47\% predicted normal (range 13-101\%) for $\mathrm{FEV}_{1}, 66 \%$ predicted normal (range 10-109\%) for FVC, and $18 \%$ predicted normal (range $1-115 \%$ ) for $\mathrm{FEF}_{25-75 \%}$.

\section{STUDY DESIGN}

$\mathrm{BMD}\left(\mathrm{g} / \mathrm{cm}^{2}\right)$ measurements were made at the following sites: lumbar spine (L2-L4), right femoral neck, and total body using a Lunar DPX-L densitometer (Lunar Corporation, Madison, WI, USA). All scan files were analysed using software version 1.34. To estimate the influence of bone size, bone mineral apparent density (BMAD, $\left.\mathrm{g} / \mathrm{cm}^{3}\right)^{20}$ was measured in the adolescents at the lumbar spine.

Lateral chest radiographs were requested on a sample of patients and the degree of thoracic vertebral wedging calculated by expressing the difference in the anterior and posterior vertebral heights as a percentage of the latter. ${ }^{5}$

Blood was sampled for measurement of liver function tests, calcium, phosphate, 25-OH vitamin $\mathrm{D}$, follicle stimulating hormone (FSH), luteinising hormone (LH), oestradiol (women), testosterone (men), and thyroid function. Sexual maturation on examination was described as stage 1 to stage 5, preadolescent to maturity. Women were asked about their age at menarche, their menstrual cycle, and if they had any history of secondary amenorrhoea. Details of treatment with oral or inhaled corticosteroids and the oral contraceptive pill were noted.

All patients were asked to complete a four day prospective unweighed diet and enzyme diary with one day during the weekend. Patients received verbal instructions before completing the diary. A standardised booklet was used. Mean daily intake of energy, protein, fibre, phosphorus, and calcium was calculated from completed records on computer using the Microdiet Program (University of Salford, UK). Results were expressed as a percentage of the estimated average requirement (EAR) or reference nutrient intake (RNI) standardised for age and sex. Daily lipase intake per $\mathrm{kg}$ of body weight was calculated.

Exercise was assessed by a seven day activity recall questionnaire. ${ }^{21}$ All patients were interviewed by one of the researchers (SPC) and activities classified by MET values. One MET is the energy expended by a person at rest (3.5 $\left.\mathrm{ml} \mathrm{O}_{2} / \mathrm{kg} / \mathrm{min}\right)$.

\section{ANALYSIS OF BMD}

The WHO diagnostic classifications for osteoporosis and osteopenia established in women were used. Normal BMD is within 1SD of the young adult reference mean value. Osteopenia has BMD values between 1SD and 2.5SD and osteoporosis values are $2.5 \mathrm{SD}$ or more below the young normal adult mean.

Comparison of patient BMD values were made with a normal reference population by conversion to a $\mathrm{T}$ score: the sex specific mean $\mathrm{BMD}$ of the young normal reference population was subtracted from the patients BMD value and this figure was divided by the standard deviation of the mean BMD of the young normal reference population. In this study a local reference population was used for the adult female lumbar spine and femoral neck, ${ }^{22}$ the manufacturer's UK reference range was used for total body. For adult men the manufacturer's reference ranges for UK men were used. For the adolescents, in the absence of a UK adolescent reference range derived on a Lunar densitometer, the manufacturer's USA Caucasian adolescent reference range was used and for BMAD of the lumbar spine a Dutch reference population was used. ${ }^{23} \mathrm{~T}$ scores based on mean data from 20-40 year old subjects rather than age matched $\mathrm{Z}$ scores were used for comparison since the WHO definitions for osteopenia and osteoporosis are based on these values. The mean age of the adolescent group was over 18 years and young normal data start at 20 years.

\section{STATISTICAL ANALYSIS}

The univariate relationships between bone density measurements (lumbar spine and femoral neck BMD, total body bone mineral density (TBBMD), and total body bone mineral content (TBBMC)) and the dichotomous variables were assessed using the MannWhitney $U$ test. Relationships between the bone density measurements and the continuous variables were assessed by testing the 


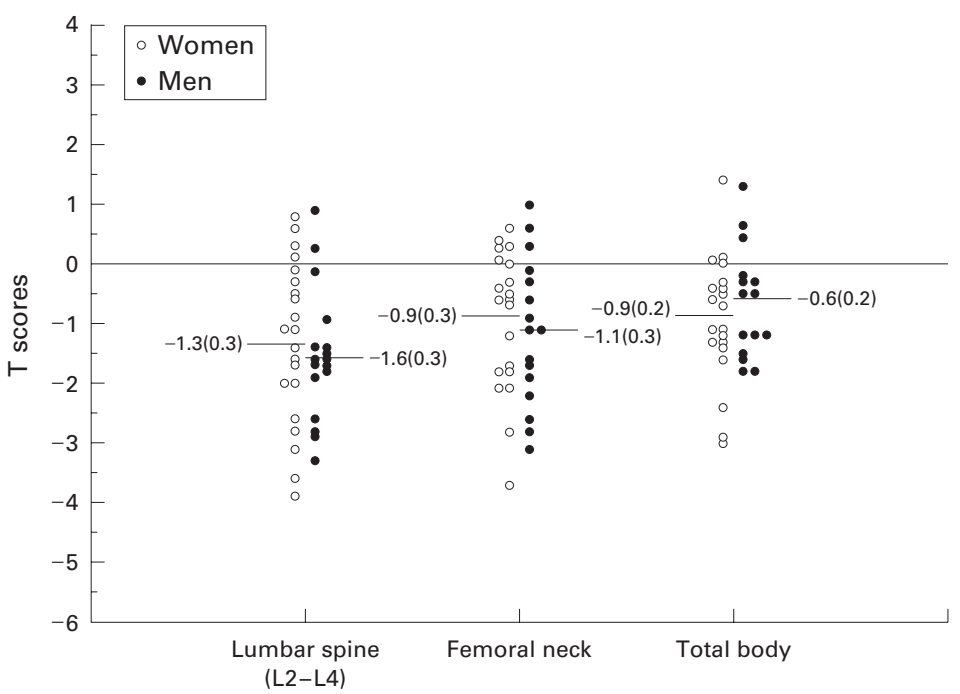

Figure 1 Distribution of mean (SE) sex specific CF adolescent $T$ scores at the three measurement sites.

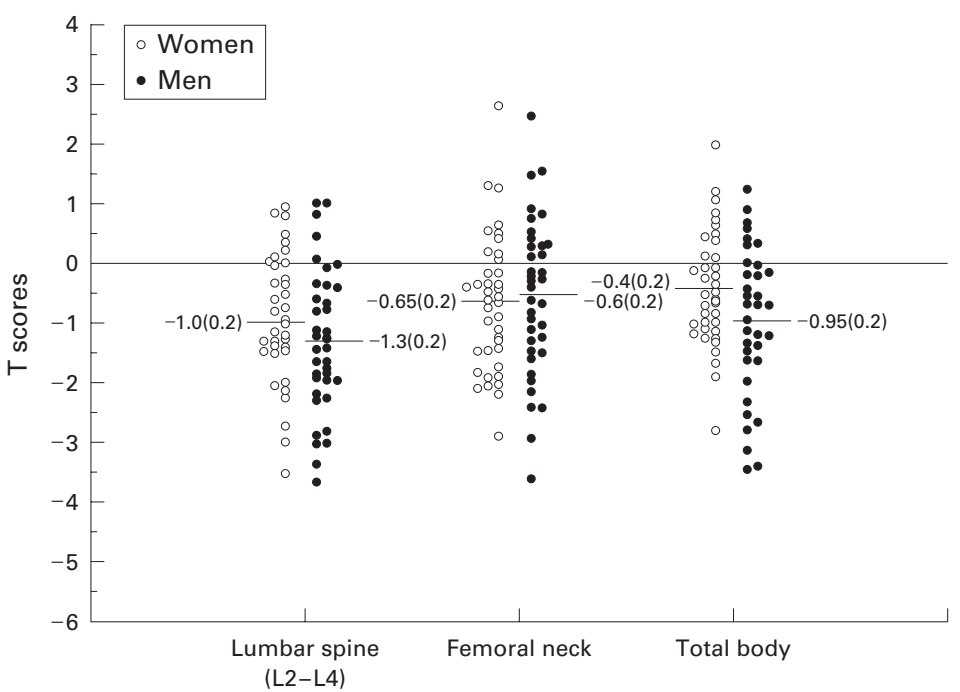

Figure 2 Distribution of mean (SE) sex specific CF adult $T$ scores at the three measurement sites.

significance of the Spearman rank correlation coefficient. A significant association was defined by a value of $p<0.05$. The bone measurements were then modelled using multiple linear regression to determine which of the significantly associated variables predicted bone mineral measurements whilst allowing for the effects of the others. In particular, age category (above or below 20 years of age) and sex were included in all of the models. For the main analysis backward elimination was used, modelling the largest possible patient group at each step and then rejecting the least significant pre-

Table 2 Spearman correlation coefficients between BMD at various sites with percentage predicted indices of disease severity

\begin{tabular}{llllllll}
\hline & SK score & BMI & FEV & FVC & FEF & CXR & IV \\
\hline Lumbar spine & 0.37 & 0.37 & $0.29^{\star}$ & 0.32 & $0.28^{\star}$ & $-0.27^{\star \star}$ & -0.42 \\
Femoral neck & 0.51 & $0.28^{\star}$ & $0.29^{\star}$ & 0.35 & 0.35 & -0.38 & -0.34 \\
Total body & 0.53 & 0.48 & 0.40 & 0.38 & 0.41 & -0.41 & -0.50 \\
\hline
\end{tabular}

All $\mathrm{p}<0.001$ except ${ }^{\star} \mathrm{p}<0.005,{ }^{\star \star} \mathrm{p}<0.01$.

SK score = Shwachman-Kulczycki clinical score; $\mathrm{BMI}=$ body mass index; $\mathrm{FEV}_{1}=$ forced expiratory volume in one second; FVC $=$ forced vital capacity; FEF $=$ forced expiratory flow rate; CXR $=$ Northern chest radiography score IV $=$ number of intravenous antibiotic treatments in the previous five years. dictors. Interactions between significant main effects and each of sex and age group were also assessed.

\section{Results}

The distribution of the sex specific $\mathrm{T}$ scores at the three measurement sites are shown in figs 1 and 2. The $\mathrm{T}$ scores at all sites were significantly reduced $(\mathrm{p}=0.01-0.001)$. The greatest deficits were observed with the BMD derived $\mathrm{T}$ scores at the lumbar spine independent of sex. The mean (SE) femoral neck BMD of male adolescents was $1.023(0.1)$ with a $\mathrm{T}$ score of -1.13 (1.2) while the corresponding values for adult males were $0.99(0.17)$ and -0.56 (1.3). This anomaly may reflect low subject numbers in the male femoral neck adolescent reference age range used in this study. BMAD $\mathrm{T}$ scores in the adolescent lumbar spine were reduced for both men $(-0.79$ (1.0)) and women $(-0.69(0.8))$. BMD $\mathrm{T}$ scores at the same site in these patients were -1.57 (1.1) and -1.31 (1.3), respectively. Male adolescent and adult TBBMC values were 2422 (251) g and 2545 (463) g, respectively; the corresponding values for women were 1909 (357) g and 2052 (300) g.

Twenty nine men (55\%) and 26 women (43\%) had osteopenia. Thirteen men $(25 \%)$ and eight women (13\%) had osteoporosis at one or more sites, with men having a slightly higher prevalence of osteoporosis at all sites. The prevalence at all three sites in adolescents and adults was similar for both females $(57 \%$, $38 \%, 50 \%$ compared with $54 \%, 38 \%, 29 \%$ ) and males $(71 \%, 56 \%, 47 \%$ compared with $62 \%, 40 \%, 46 \%)$. A comparison of the prevalence of osteopenia and osteoporosis derived from BMD and BMAD for the adolescent lumbar spine site indicated a higher prevalence for BMD (67\% versus $44 \%$ ).

Univariate analysis allowing for age and sex showed no significant association between BMD measurements and genotype, presence or absence of diabetes mellitus or liver disease, age at menarche or use of the oral contraceptive pill, length of treatment with inhaled corticosteroids, 25-OH vitamin D level, calcium, phosphate, energy or protein intake. A significant relationship $(p<0.05)$ was found between all BMD measurements and indices of disease severity: SK and Northern chest radiographic scores, $\mathrm{BMI}$ \% predicted $\mathrm{FEV}_{1}, \mathrm{FVC}$, and $\mathrm{FEF}_{25-75 \%}$, and the number of intravenous antibiotic treatments in the last five years (table 2). Reduced BMD was associated with more severe disease. Greater daily physical activity as estimated by the METS score was significantly associated with greater femoral neck BMD, TBBMD, and TBBMC.

Eighteen (16\%) and $50(44 \%)$ patients had received oral or inhaled corticosteroids, respectively, at some time. Median lengths of treatment were 17 months (oral) and 24 months (inhaled). Oral corticosteroid use and length of treatment were associated with reduced $\mathrm{BMD}$ in the lumbar spine and femoral neck, and use of inhaled corticosteroids was associated with decreased lumbar spine BMD, TBBMD, and TBBMC. When the steroid user 
groups (inhaled and oral) were combined and compared with the non-steroid groups, the prevalence of osteopenia at the lumbar spine site was identical (45\%). However, there was a greater prevalence of osteoporosis in the steroid group ( $26 \%$ versus $7 \%$ ). There was a significant difference $(\mathrm{p}<0.0004)$ between the $\mathrm{T}$ scores at the lumbar spine of the steroid groups compared with the non-steroid groups (fig 3).

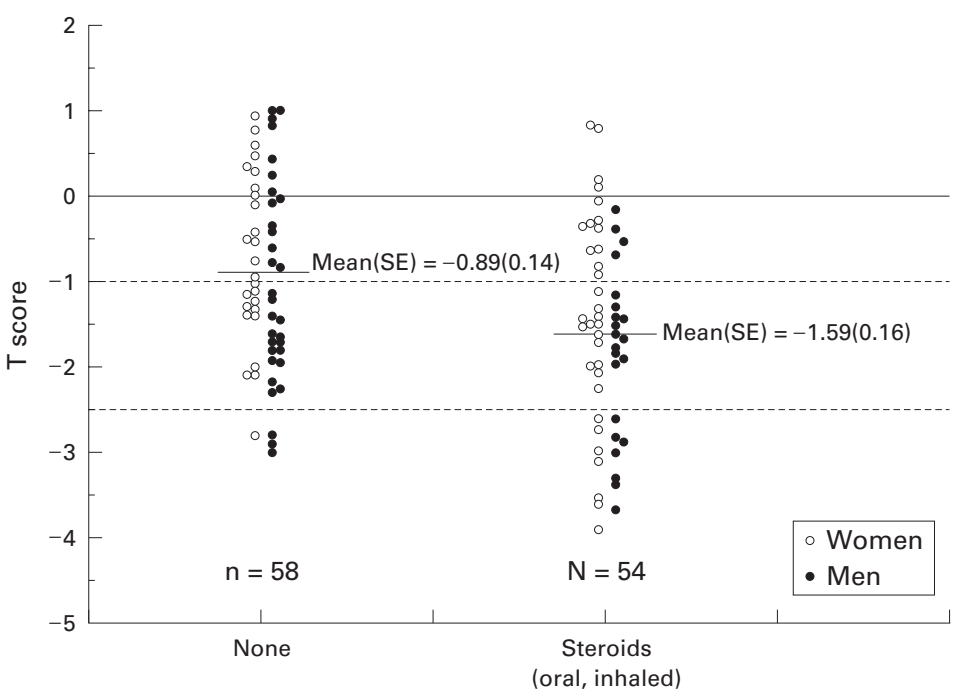

Figure 3 Distribution of mean (SE) sex specific CF adult/adolescent $T$ scores at the lumbar spine (L2-L4) grouped by corticosteroid use.

Table 3 Multiple regression analysis for lumbar spine BMD

\begin{tabular}{lclccc}
\hline Variable & Coefficient $b$ & $\begin{array}{l}\text { Standard error } \\
(S E(b))\end{array}$ & $p$ value & $\begin{array}{l}\text { Lower } \\
95 \% C L\end{array}$ & \multicolumn{1}{l}{$\begin{array}{l}\text { Upper } \\
95 \% C L\end{array}$} \\
\hline Intercept & 0.587 & 0.114 & $<0.0001$ & 0.360 & 0.814 \\
Sex (F vs M) & 0.074 & 0.026 & 0.005 & 0.023 & 0.126 \\
Age 20+ & 0.020 & 0.026 & 0.439 & -0.032 & 0.072 \\
SK score & 0.0032 & 0.00095 & 0.001 & 0.0013 & 0.005 \\
BMI & 0.012 & 0.006 & 0.036 & 0.001 & 0.024 \\
No. IV antibiotic treatments & -0.014 & 0.007 & 0.045 & -0.027 & 0.000 \\
Oral steroids & -0.082 & 0.034 & 0.017 & -0.149 & -0.015
\end{tabular}

SK score = Shwachman-Kulczycki clinical score; $\mathrm{BMI}=$ body mass index; $\mathrm{CL}=$ confidence limit. 96 patients had complete data on these variables.

Adjusted $R^{2}=0.33$; residual standard error $=0.113$.

Table 4 Multiple regression analysis for femoral neck BMD

\begin{tabular}{lclccc}
\hline Variable & Coefficient $b$ & $\begin{array}{l}\text { Standard error } \\
(S E(b))\end{array}$ & p value & $\begin{array}{l}\text { Lower } \\
95 \% C L\end{array}$ & $\begin{array}{l}\text { Upper } \\
95 \% C L\end{array}$ \\
\hline Intercept & 0.611 & 0.072 & $<0.0001$ & 0.469 & 0.754 \\
Sex (F vs M) & -0.012 & 0.026 & 0.647 & -0.064 & 0.040 \\
Age 20+ & -0.012 & 0.026 & 0.650 & -0.064 & 0.040 \\
SK score & 0.0055 & 0.009 & $<0.0001$ & 0.0038 & 0.0073 \\
Oral steroids & -0.078 & 0.035 & 0.027 & -0.147 & -0.009 \\
\hline
\end{tabular}

SK score $=$ Shwachman-Kulczycki clinical score; $\mathrm{CL}=$ confidence limit .

100 patients had complete data on these variables.

Adjusted $R^{2}=0.32$; residual standard error $=0.123$.

Table 5 Multiple regression analysis for total body bone mineral density (TBBMD)

\begin{tabular}{lclccc}
\hline Variable & Coefficient $b$ & $\begin{array}{l}\text { Standard error } \\
(S E(b))\end{array}$ & $p$ value & $\begin{array}{l}\text { Lower } \\
95 \% C L\end{array}$ & $\begin{array}{l}\text { Upper } \\
95 \% C L\end{array}$ \\
\hline Intercept & 0.783 & 0.0066 & $<0.0001$ & 0.651 & 0.914 \\
Sex (F vs M) & -0.050 & 0.021 & 0.018 & -0.092 & -0.009 \\
Age 20+ & 0.030 & 0.016 & 0.071 & -0.003 & 0.062 \\
SK score & 0.0025 & 0.0006 & 0.0002 & 0.0012 & 0.0037 \\
BMI & 0.0084 & 0.0037 & 0.024 & 0.0011 & 0.0157 \\
Inhaled steroids (men) & -0.070 & 0.021 & 0.002 & -0.112 & -0.027 \\
Inhaled steroids (women) & -0.010 & 0.021 & 0.643 & -0.051 & -0.032 \\
\hline
\end{tabular}

SK score $=$ Shwachman-Kulczycki clinical score $; \mathrm{BMI}=$ body mass index $; \mathrm{CL}=$ confidence limit . 97 patients had complete data on these variables.

Adjusted $R^{2}=0.47$; residual standard error $=0.0703$.
Multiple regression analysis showed that disease severity and corticosteroid use were good predictors of BMD (tables 3-6). All clinical indices of the former were good predictors in their own right but were highly correlated. The SK score explained most of the variation resulting from these indices. As expected from the differences in body size, female sex was significantly associated with lower TBBMD and TBBMC, but nonetheless predicted higher BMD at the lumbar spine. There was no significant effect of sex on BMD at the femoral neck. The model for TBBMC showed a positive association with a higher dietary fibre intake.

Age group was not significant for any of the final models. No interactions were found to be significant for lumbar spine BMD, femoral neck BMD, or TBBMC. The interaction between sex and inhaled corticosteroid was significant for TBBMD (table 5). Men on inhaled corticosteroid treatment tended to have lower levels of TBBMD, whereas for women there was little effect of inhaled corticosteroids.

The percentage of thoracic vertebral wedging was assessed in 66 patients. Seventeen $(26 \%)$ had $20 \%$ or more wedging of at least one thoracic vertebrae. Six of these had osteopenia and five had osteoporosis.

All patients were fully sexually mature on examination and there were no abnormalities in FSH, LH, or oestradiol levels. Four men, two with osteopenia and one with osteoporosis, had low testosterone levels with normal levels of gonadotrophic stimulating hormones. Median age at menarche was 14 years (range $9-18)$. Nine women (15\%) reported episodes of secondary amenorrhoea of two months or more. Twenty one women had taken an oral contraceptive pill for a median of four years (range 3 months to 9 years).

Analysis of the four day dietary intake showed the following median, minimum and maximum values: energy $123 \%$ EAR (56$252 \%$ ), protein $214 \%$ RNI (101-464\%), fibre $10.5 \mathrm{~g} /$ day (1.3-47.3 g), phosphate $284 \% \mathrm{RNI}$ (101-609\%), calcium 175\% RNI (54-369\%), percentage total energy from protein $15.3 \%$ $(9.2-24.9 \%)$. Mean lipase intake was 6500 units/kg body weight/day. None of 98 patients in whom vitamin $\mathrm{D}$ was measured had levels below the lower limit of the normal range. The mean vitamin $\mathrm{D}$ level was $18 \mathrm{ng} / \mathrm{ml}$ (range 3-41). However, 39.8\% had vitamin D insufficiency with levels of $<15 \mathrm{ng} / \mathrm{ml}^{24}$ Three patients had low blood calcium levels, one with osteoporosis and two with osteopenia. Four other patients, two with osteopenia, had low blood phosphate levels. Seventeen patients $(15 \%), 14$ of whom had osteopenia or osteoporosis, had a history of traumatic fracture.

\section{Discussion}

Reduced BMD is common in adult patients with CF; $79 \%$ of 53 men and $56 \%$ of 61 women in this study had osteopenia or osteoporosis at one or more sites. Previous 
Table 6 Multiple regression analysis for total body bone mineral content (TBBMC)

\begin{tabular}{lccccc}
\hline Variable & Coefficient $b$ & $\begin{array}{l}\text { Standard error } \\
(S E(b))\end{array}$ & p value & $\begin{array}{l}\text { Lower } \\
95 \% C L\end{array}$ & $\begin{array}{l}\text { Upper } \\
95 \% C L\end{array}$ \\
\hline Intercept & 53 & 477 & 0.912 & -899 & 1005 \\
Sex (F vs M) & -369 & 71 & $<0.0001$ & -511 & -227 \\
Age 20+ & 65.6 & 78.2 & 0.405 & -90.6 & 221.7 \\
Diabetes mellitus & -277 & 77 & 0.001 & -431 & -122 \\
SK score & 10.7 & 3.8 & 0.006 & 3.2 & 18.3 \\
BMI & 51.7 & 17.7 & 0.005 & 16.5 & 87.0 \\
Northern score & 41.2 & 14.5 & 0.006 & 12.3 & 70.2 \\
Fibre intake & 12.5 & 5.5 & 0.027 & 1.4 & 23.5 \\
\hline
\end{tabular}

SK score = Shwachman-Kulczycki clinical score; $\mathrm{BMI}=$ body mass index; $\mathrm{CL}=$ confidence limit. 76 patients had complete data on these variables.

Adjusted $R^{2}=0.61$; residual standard error $=279$.

studies have also reported more osteoporosis in men than in women. ${ }^{4}$

Haworth et $a l^{15}$ found BMD significantly lower in men in a large unselected population of adults with CF despite the men and women having comparable lung disease and nutritional indices and there being no evidence of male hypogonadism. Mean (SD) SK clinical scores in our patients showed the men to be significantly healthier (adolescent scores of 78 (13) and 68 (15) in men and women, respectively $(\mathrm{p}<0.05)$ and adult scores of 75 (15) and $66(14)$, respectively $(\mathrm{p}<0.001))$. Only four men had low testosterone levels. The sex difference in BMD is not understood but may be partly explained by the higher early mortality rate in women ${ }^{1}$ which removes the most severely affected female patients from the study population.

The BMD measurement is an areal derived density and does not correct for the anteriorposterior dimension of the bone and may lead in subjects with reduced body size, such as patients with $\mathrm{CF}$, to a falsely low interpretation of BMD. ${ }^{25}$ BMAD measurements take account of bone size. However, the BMAD derived $\mathrm{T}$ score for the lumbar spine in the adolescents was also significantly reduced $(-0.79$ in men and -0.69 in women) and $44 \%$ had osteopenia or osteoporosis according to WHO criteria for BMD measurements. Currently no such criteria exist for the interpretation of BMAD calculations. Haworth et $a l^{15}$ documented similar BMD changes when patients were scanned by DXA or quantitative computed tomography, a volumetric measure of BMD. The smaller body size of patients with CF does not appear to exert a significant effect.

Univariate and multiple regression analysis showed increased disease severity and corticosteroid treatment as significant risk factors for inadequate BMD. Variable indices of nutritional and respiratory well being, as well as the overall SK score, all correlated significantly with BMD measurements. TBBMD showed the best correlation with all measures of clinical severity (table 2). This may be the best measurement to consider when investigating the effects of disease severity on bone mineral status.

Although a few studies have found no relationship between BMD status and respiratory function tests, ${ }^{6}{ }^{13-14}$ SK score,${ }^{626}$ or chest radiographic score, ${ }^{26}$ the papers by Aris and Donovan $^{13}{ }^{14}$ were restricted to severely compromised patients with a narrow range of respiratory function. Disease severity has shown important associations with reduced BMD when the former was assessed by respiratory function, ${ }^{9}{ }^{10}$ SK score, ${ }^{4} 7827$ chest radiographic scores, ${ }^{79}$ demand for antibiotic treatment, or BMI status. ${ }^{568101427}$

Baroncelli et al showed a marked reduction in TBBMC in young adults compared with prepubertal patients, suggesting that disease severity progressively affects bone mineral status. ${ }^{7}$ The only other study in a large heterogenous adult CF population ${ }^{15}$ importantly found a clear relationship between BMD and disease severity. Our data highlight this close association. Eradication protocols for early Pseudomonas aeruginosa infection, ${ }^{28}$ intensive treatment of respiratory infection, maintenance of lung function, and achievement of normal growth through frequent contact with specialist dietetic services from the time of diagnosis are all essential if we are to avoid early osteoporosis in these patients.

The prevalence of osteoporosis in the corticosteroid user group was $26 \%$ compared with $7 \%$ in the non-user group. Oral corticosteroid use was independently associated with decreased $\mathrm{BMD}$ in the lumbar spine and femoral neck, and inhaled corticosteroids with low TBBMD. Previous studies have shown inconsistencies in their conclusions about the aetiological importance of corticosteroid use in $\mathrm{CF}$ associated osteopenia and osteoporosis. No association $^{6913}$ and significant corticosteroid effects $^{827}$ have been reported. Patients receiving corticosteroids have shown less annual gain in $\mathrm{BMD},{ }^{27}$ less bone formation, and an increased vertebral fracture rate. ${ }^{12}$ Our study on data from a large number of adult patients emphasises the danger of widespread corticosteroid use in the care of patients with CF. Although possibly relieving immediate respiratory discomfort, such treatment significantly increases the risk of later osteoporosis and its attendant problems. It should only be prescribed long term if of proven benefit to the individual.

Multiple risk factors put patients with $\mathrm{CF}$ at risk of developing osteopenia and osteoporosis. Children with CF may fail to reach their peak bone mass, ${ }^{3489}$ and the recognition that osteopenia is common at all ages suggests that both inadequate bone mineral accretion as well as increased bone loss are important aetiological factors. Our results support this. We found no significant differences in sex specific TBBMD between adult and adolescent patients, suggesting that the latter group had already almost achieved their peak TBBMC. There was a similar prevalence of low BMD in both age groups.

Delayed puberty may interfere with peak bone mineral accretion, ${ }^{8} 14$ and hypogonadism in adult patients may cause accelerated bone loss. ${ }^{68}$ All patients in this study were sexually mature on clinical examination. No significant correlation was found between BMD and age at menarche. Only $15 \%$ of women reported amenorrhoea of two months or more, and there was no biochemical evidence of primary or secondary hypogonadism except for four men 
with low testosterone but normal FSH and $\mathrm{LH}$ levels. Low testosterone levels have been reported by others ${ }^{6814}$ and should be measured in all patients with reduced BMD.

Physical activity has been reported both as having little predictive value for bone mineral status $^{58}$ and as being of some importance..$^{1527}$ We found a significant association between physical activity calculated according to the previous week's level and femoral neck BMD, TBBMD, and TBBMC on univariate analysis, but no significant association on further multiple regression analysis after allowing for disease severity and corticosteroid treatment. Accurate assessment is, however, difficult. Activity will vary considerably according to how the patient feels at any particular time. Recall, even over one week, can be difficult and any single week is likely to be unrepresentative of true overall activity levels. Children with CF should nonetheless be encouraged to take regular weight bearing exercise where their bone health permits, as osteoporosis in the general population has been associated with reduced activity levels.

Patients attending a CF centre will have regular and frequent contact with the specialist dietitian and it is not surprising that median dietary intake was in excess of the EAR and RNI. Multiple regression analysis showed a higher fibre intake independently associated with greater TBBMC. We believe the fibre intake (which showed a positive correlation with phosphate, calcium, energy and protein intake, and with BMI) is a marker of better overall nutrition. Calcium and phosphate levels were normal in all but seven patients. Although no patient had frank vitamin D deficiency, $40 \%$ had insufficient blood levels, a figure very similar to the $38 \%$ found by Haworth et al. ${ }^{15}$ In both groups of patients standard vitamin D supplementation is practised, approximately $800 \mathrm{IU}$ daily adjusted according to serum levels. Inadequate sunlight exposure may be a significant factor. ${ }^{15}$ Patients with levels within the normal range but still recognised as insufficient ${ }^{24}$ should be considered for increased supplements and receive advice about exposure to sunlight. Neither dietary intake of protein, calcium, or phosphate, nor vitamin D levels had any association with BMD status. Even where low vitamin $\mathrm{D}$ levels have been found, they have not correlated significantly with BMD. $^{8} 1415$

With the average age of death for patients now at just over 30 years of age ${ }^{1}$ and life expectancy for today's children with CF predicted to be over 45 years, ${ }^{28}$ the impact of a widespread reduction in BMD is likely to be realised in adult patients suffering osteoporotic fractures and exaggerated respiratory difficulties from the pain, debilitation, and chest wall deformities consequent upon thoracic vertebral body collapse. Seventeen (26\%) of the 66 patients in whom vertebral body wedging was assessed had pronounced anterior collapse. Eleven of these 17 patients had significantly reduced BMD. Grey reported a similar incidence in $31 \%$ of $16 \mathrm{New}$ Zealand patients. ${ }^{5}$
Fourteen of 17 study patients who reported a history of fracture had osteopenia or osteoporosis. Although some studies report a low fracture rate, ${ }^{6}{ }^{29}$ patients with CF are at an increased risk. ${ }^{7-9} 1415$ The heightened incidence of fracture is particularly seen in patients with severe $\mathrm{CF}$ awaiting lung transplantation. ${ }^{13}$ The varying histories may reflect different compositions of the populations studied (more or less severely affected patients), the effects of different lifestyles (more or less physical activity), chance, or accuracy of recall. Overall, the data suggest that, with a growing number of middle aged patients with CF, we are likely to see more osteoporosis dependent clinical problems.

In conclusion, most patients attending an adult CF centre showed a significant deficiency in bone mineralisation. These patients are at risk of fracture from minimal trauma. We have shown pronounced anterior vertebral collapse in $26 \%$ of 66 patients investigated for this potential complication. Rib and thoracic vertebral compression fractures are likely to impair cough efficiency and the ability to perform chest physiotherapy, potentially accelerating respiratory decline.

We have documented a clear relationship between reduced BMD and corticosteroid use and recommend judicious use of corticosteroid therapy. We have emphasised the relationship between low BMD and disease severity. In the absence of proven treatment for osteopenia in $\mathrm{CF}$, early, continued, and intensive treatments to eradicate or minimise respiratory tract infection appear to be the optimal means available to reduce bone mineral losses. Our results show TBBMD to correlate best with markers of disease severity and we recommend that further studies examining the effects of $\mathrm{CF}$ pathology on bone status should include this measurement.

Adult patients with CF show a high prevalence of vitamin D insufficiency. Approaches to reverse this inadequacy should be further explored. Almost all bone mineral is accrued by the end of adolescence. ${ }^{30}{ }^{31}$ The bone studies in our adolescent population showed insufficient bone mineral accretion. Research should also be directed at developing treatment protocols that allow children with CF to achieve normal bone mineral deposition.

1 Dodge JA, Morison S, Lewis PPA, et al. Incidence, population, and survival of cystic fibrosis in the United Kingdom, 1968-95. Arch Dis Child 1997;77:493-6.

2 Hui SL, Selmenda CS, Johnston CC Jr. Age and bone mass as predictors of fracture in a prospective study. $\mathcal{F}$ Clin Invest 1988;81:1804-9.

3 Mischler EH, Chesney PJ, Chesney RW, et al. Demineralisation in cystic fibrosis. Am $\mathcal{F}$ Dis Child 1979;133:632-5.

4 Gibbens DT, Gilsanz V, Boechat MI, et al. Osteoporosis in Gibbens DT, Gilsanz V, Boechat MI, et al. Oste
cystic fibrosis. $\mathcal{F}$ Pediatr 1988;113:295-300.

5 Grey AB, Ames RW, Matthews RD, et al. Bone mineral density and body composition in adult patients with cystic fibrosis. Thorax 1993;48:589-93.

6 Bachrach LK, Loutit CW, Moss RB, et al. Osteopenia in adults with cystic fibrosis. Am $\mathcal{F}$ Med 1994;96:27-34.

7 Baroncelli GI, Luka FD, Magazzu G, et al. Bone demineralisation in cystic fibrosis: evidence of imbalance between bone formation and degradation. Pediatr Res 1997;41:397-403.

8 Bhudhikanok GS, Lim J, Marcus R, et al. Correlates of osteopenia in patients with cystic fibrosis. Pediatrics 1996;97:103-11.

9 Henderson RC, Madsen CD. Bone density in children and adolescents with cystic fibrosis. F Pediatr 1996;128:28-34. 
10 Henderson RC, Madsen CD. Bone mineral content and body composition in children and young adults with cystic body composition in children and youn
fibrosis. Pediatr Pulmonol 1999;27:80-4.

11 Ferrari SL, Nicod LP, Hamacher J, et al. Osteoporosis in patients undergoing lung transplantation. Eur Respir $\mathcal{f}$ 1996;9:2378-82.

12 Shane E, Silverberg SJ, Donovan D. Osteoporosis in lung transplantation candidates with end stage pulmonary disease. Am F Med 1996;101:262-9.

13 Donovan DS, Papadopoulos A, Staron RB, et al. Bone mass and vitamin $\mathrm{D}$ deficiency in adults with advanced cystic fibrosis lung disease. Am f Respir Crit Care Med 1998;158: 1892-9.

14 Aris RM, Renner JB, Winders AD, et al. Increased rate of fractures and severe kyphosis: sequelae of living into adulthood with cystic fibrosis. Ann Intern Med 1998;128:186-93.

15 Haworth CS, Selby PL, Webb AK, et al. Low bone mineral density in adults with cystic fibrosis. Thorax 1999;54:961-7.

16 Freeman JV, Cole TJ, Chinn S, et al. Cross sectional stature and weight reference curves for the UK, 1990. Arch Dis Child 1995;53:17-24

17 Cole TJ, Freeman JV, Preece MA. Body mass index reference curves for the UK, 1990. Arch Dis Child 1995;73: 25-9.

18 Shwachman H, Kulczycki LL. Long-term study of 105 patients with cystic fibrosis: studies made over a 5-14 year period. Am F Dis Child 1958;96:6-15.

19 Conway SP, Pond MN, Bowler I, et al. The chest radiograph in cystic fibrosis: a new scoring system compared with the Chrispin-Norman and Brasfield scores. Thorax 1994;49: $860-2$.

$20 \mathrm{Lu}$ PW, Cowell CT, Lloyd-Jones SA, et al. Volumetric bone mineral density in normal subjects, aged 5-27 years. 7 Clin Endocrinol Metab 1996;81:1586-90.

21 Wilson PWF, Paffenbarger RS, Morris JN, et al. Assessment methods for physical activity and physical fitness in population studies: report of a NHLBI workshop. $A m$ population studies: report
Heart $\mathcal{f} 1986 ; 111: 1177-92$.
22 Truscott JG, Oldroyd B, Simpson M, et al. Variation in lumbar spine and femoral neck bone mineral density measured by dual energy X-ray absorption: a study of 329 normal women. Br F Radiol 1993;66:514-21.

23 Boot AM, de Ridder MAJ, Pols HAP, et al. Bone mineral density in children and adolescents: relation to puberty, calcium intake, and physical activity. 7 Clin Endocrinol Metab 1997;82:57-62.

24 Thomas MK, Lloyd-Jones DM, Thadhani RI, et al. Hypovitaminosis $\mathrm{D}$ in medical inpatients. $N$ Engl $f \mathrm{Med}$ 1998;338:777-83.

25 Prentice A, Parsons TJ, Cole TJ. Uncritical use of bone mineral density in absorptiometery may lead to size-related artefacts in the identification of bone mineral determinants. Am F Clin Nutr 1994;60:837-42.

26 Shaw N, Bedford C, Heaf D, et al. Osteopenia in adults with cystic fibrosis. Am f Med 1995;99:690-1.

27 Bhudhikanock GS, Wang MC, Marcus R, et al. Bone acquisition and loss in children and adults with cystic fibrosis: a longitudinal study. F Pediatr 1998;133:18-27.

28 Frederiksen B, Lanng S, Koch C, et al. Improved survival in the Danish center- treated cystic fibrosis patients: result of aggressive treatment. Pediatr Pulmonol 1996;21:153-8.

29 Hahn TJ, Squires AE, Holstead LR, et al. Reduced serum 25-hydroxy vitamin 14 concentration and disordered mineral metalbolism in patients with cystic fibrosis. $\mathcal{F}$ Pediatr 1979;94:38-42.

30 Glastre C, Braillon P, David L, et al. Measurement of bone mineral content of the lumbar spine by dual energy X-ray absorptiometery in normal children: correlations with growth parameters. If Clin Endocrinol Metab 1990;70: 1330-3.

31 Bailey DA, Saskatchew AN. Pediatric bone mineral accrual study: bone mineral acquisition during the growing years. Int f Sports Med 1997;18(Suppl 3):S191-4. 